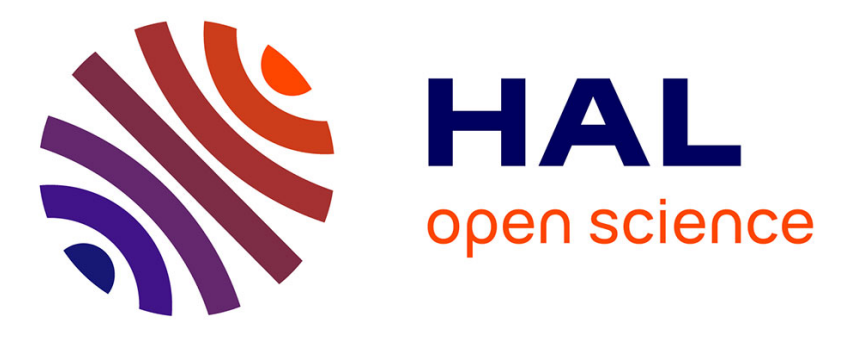

\title{
Decomposition of the switchback boundary on MHD wave modes.
}

\author{
Vladimir Krasnoselskikh, Andrea Larosa, Thierry Dudok de Wit, Oleksiy \\ Agapitov, Clara Froment, Matthieu Kretzschmar, Vamsee Jagarlamudi, \\ Marco Velli, Keith Goetz, Peter Harvey, et al.
}

\section{To cite this version:}

Vladimir Krasnoselskikh, Andrea Larosa, Thierry Dudok de Wit, Oleksiy Agapitov, Clara Froment, et al.. Decomposition of the switchback boundary on MHD wave modes.. vEGU21, 2021, Online, Unknown Region. 10.5194/egusphere-egu21-15180 . insu-03559298

\section{HAL Id: insu-03559298 \\ https://hal-insu.archives-ouvertes.fr/insu-03559298}

Submitted on 7 Feb 2022

HAL is a multi-disciplinary open access archive for the deposit and dissemination of scientific research documents, whether they are published or not. The documents may come from teaching and research institutions in France or abroad, or from public or private research centers.
L'archive ouverte pluridisciplinaire HAL, est destinée au dépôt et à la diffusion de documents scientifiques de niveau recherche, publiés ou non, émanant des établissements d'enseignement et de recherche français ou étrangers, des laboratoires publics ou privés.

\section{(c)(1)}

Distributed under a Creative Commons Attribution| 4.0 International License 
EGU21-15180

https://doi.org/10.5194/egusphere-egu21-15180

EGU General Assembly 2021

(c) Author(s) 2022. This work is distributed under

the Creative Commons Attribution 4.0 License.

\title{
Decomposition of the switchback boundary on MHD wave modes.
}

\author{
Vladimir Krasnoselskikh ${ }^{1,2}$, Andrea Larosa ${ }^{3}$, Thierry Dudok de Wit ${ }^{1,3}$, Oleksiy Agapitov ${ }^{2}$, Clara \\ Froment ${ }^{1}$, Matthieu Kretzschmar ${ }^{1,3}$, Vamsee Jagarlamudi ${ }^{1}$, Marco Velli ${ }^{4}$, Stuart D. Bale ${ }^{2,5,6}$, Keith \\ Goetz $^{7}$, Peter Harvey ${ }^{2}$, Justin Kasper ${ }^{8,9,10}$, Kelly Korreck ${ }^{9}$, Davin Larson ${ }^{2}$, Robert MacDowall ${ }^{11}$, David \\ Malaspina $^{12}$, Forrest Mozer ${ }^{2}$, Marc Pulupa $^{2}$, Claire Reveillet $^{1}$, and Michael Stevens ${ }^{9}$ \\ ${ }^{1}$ CNRS-University of Orleans, LPCE, Orleans CEDEX 2, France (vkrasnos@cnrs-orleans.fr) \\ ${ }^{2}$ Space Science Laboratory, University of California at Berkeley, 94720, Berkeley, CA, USA \\ ${ }^{3}$ University of Orleans, Orleans, Cedex 2, France \\ ${ }^{4}$ Institute of Geophysics \& Planetary Physics, Department of Earth, Planetary \& Space Sciences, University of California, Los \\ Angeles, CA 90095-1567, USA \\ ${ }^{5}$ Physics Department, University of California, Berkeley, CA 94720-7300, USA \\ ${ }^{6}$ The Blackett Laboratory, Imperial College London, London, SW7 2AZ, UK \\ ${ }^{7}$ School of Physics and Astronomy, University of Minnesota, Minneapolis, MN 55455, USA \\ ${ }^{8}$ BWX Technologies, Inc., Washington, DC 20002, USA \\ ${ }^{9}$ Smithsonian Astrophysical Observatory, Cambridge, MA, 02138, USA \\ ${ }^{10} \mathrm{Climate}$ and Space Sciences and Engineering, University of Michigan, Ann Arbor, MI 48109, USA \\ ${ }^{11}$ Solar System Exploration Division, NASA/Goddard Space Flight Center, Greenbelt, MD 20771, USA \\ ${ }^{12}$ Laboratory for Atmospheric and Space Physics, University of Colorado, Boulder, CO 80303, USA
}

Switchback boundaries separate two plasmas moving with different velocities, that may have different temperatures and densities and typically manifest sharp magnetic field deflections through the boundary. They may be analyzed similarly to MHD discontinuities. The first step of their characterization consists of analysis in terms of MHD discontinuities. Such an analysis was performed by Larosa et al., (2021) who has found that $32 \%$ of them may be attributed to rotational discontinuities, $17 \%$ to tangential, about $42 \%$ to the group of discontinuities that are difficult to unambiguously define whether they are tangential or rotational, and $9 \%$ that do not belong to any of these two groups. We describe and apply hereafter for two events another approach for the characterization of the boundaries based on classification of the general type discontinuity in MHD approximation. It is based on the problem of the decay of the general type of discontinuity. It is well known [Kulikovsky and Lyubimov, 1962, Gogosov, 1959\} that general type MHD discontinuity decays on 7 separate discontinuities belonging to different types of MHD waves, namely, entropic wave, two slow mode waves, two Alfvenic waves, and two fast mode waves. Entropic wave is standing in the reference frame of the discontinuity; other wave modes are supposed to run in the opposite directions from the initial discontinuity with their characteristic velocities. Making use of plasma parameters from two sides of the boundary one can evaluate the fraction of each wave mode present in the discontinuity. We apply this method to two boundary crossings. This repartition of the discontinuity allows characterizing the deviation from Alfvenicity quantitatively. 


\section{References}

Larosa, A., et al., A\&A, 2021, (accepted)

Kulikovsky, Lyubimov, Magnetohydrodynamics, (1962)

Gogosov, V.V., Decay of the MHD discontinuity, (1959) 